\title{
FOLLOW THE ARC TO ARCTURUS
}

STAN SHADICK, 4 - 1008 Temperance St., Saskatoon, SK S7N ON6

Editor's note: Stan Shadick is an astronomy lecturer at the University of Saskatchewan and author of the 1998 Canadian Skywatcher's Trivia Calendar.

The seven stars of the Big Dipper form a well-known stellar pattern in our northern skies. This famous asterism forms the tail and hindquarters of Ursa Major, the Great Bear. Muscida emblazons the bear's nose and Tania Australis marks one of its hind legs.

During the night, as Earth spins on its axis, Bootes, the herdsman chases this celestial bear around Polaris, the North Star. Shortly after nightfall on an autumn evening, if you find the curved handle of the Big Dipper and follow the curve of its arc beyond the handle's end, you will locate Arcturus, the brightest star of Bootes constellation.

Arcturus is a giant in comparison to our Sun. Its volume is large enough to swallow 65,000 suns, yet its mass is only 4 times heavier than our sun. This star is a stellar senior citizen, having consumed its supply of hydrogen fuel that powered its central nuclear furnace during its

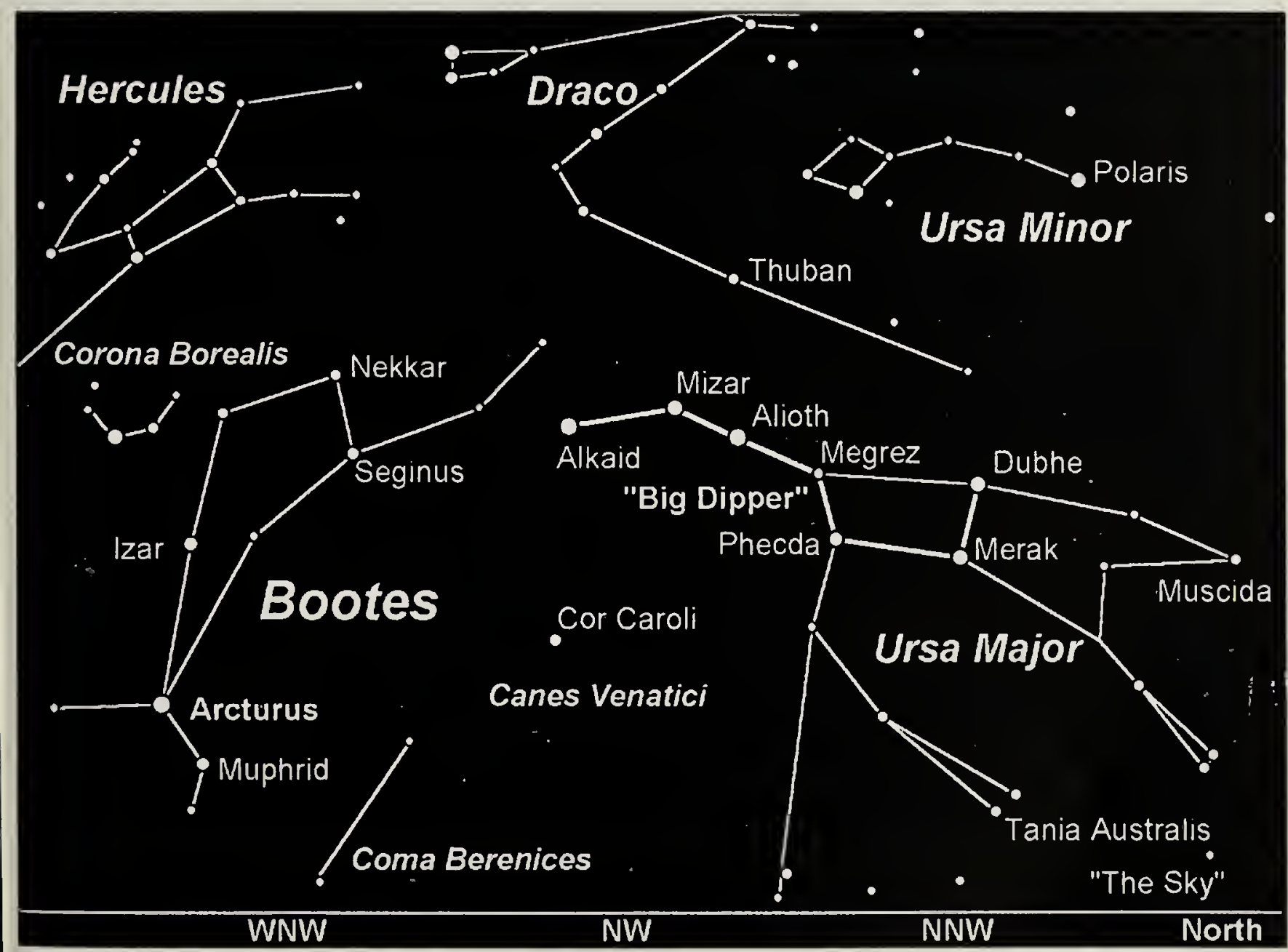

Bootes and Ursa Major above northwestern horizon about 2 hours after sunset from September through November. 
youth. The loss of core fuel led to a dramatic reorganization of the star's internal structure. Its core collapsed and a shell of remaining hydrogen surrounding the core ignited, causing the surface of the star to expand to its present diameter of 32 million $\mathrm{km}$.

Our solar system is a resident of one spiral arm of the great Milky Way galaxy. Most stars visible in the night sky are neighbours that follow us, like horses on a merry-go-round, as we orbit the centre of the Milky Way.

Arcturus is an exception. It is not a true member of our spiral arm, but an alien visitor from the more distant halo population of stars that envelopes the spiral arms like a swarm of bees. These halo stars are much older than our neighbours and are thought to represent a generation of stars that formed soon after the birth of our galaxy, over 10 billion years ago. By contrast, the Sun is relatively young, only 4.6 billion years old.

Presently only 36 light-years away, Arcturus is speeding towards us at $540,000 \mathrm{~km} / \mathrm{h}$. In the distant future, it will swing past us and shift into Virgo constellation where it will continue on its journey to rejoin other members of the halo population.
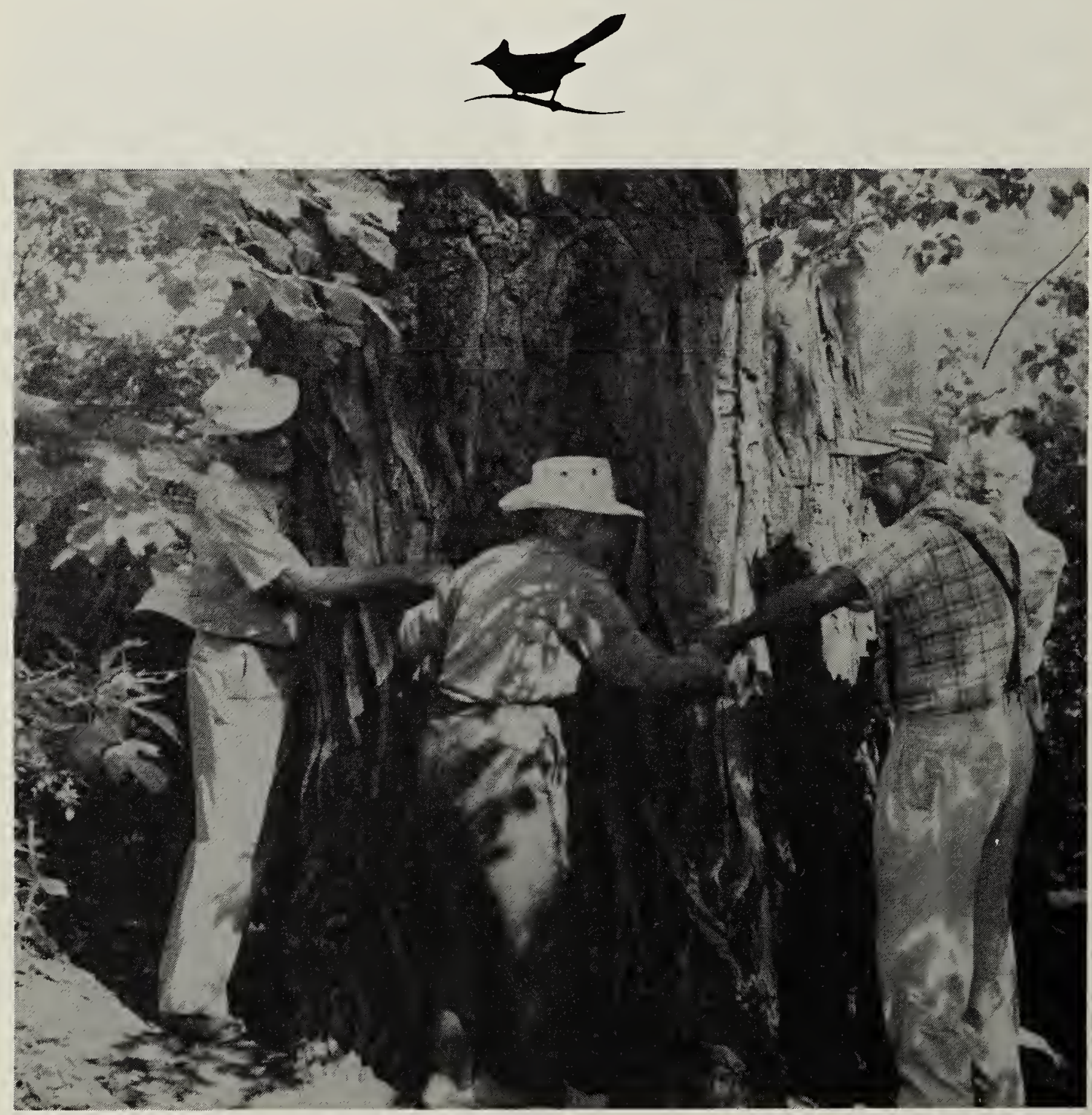



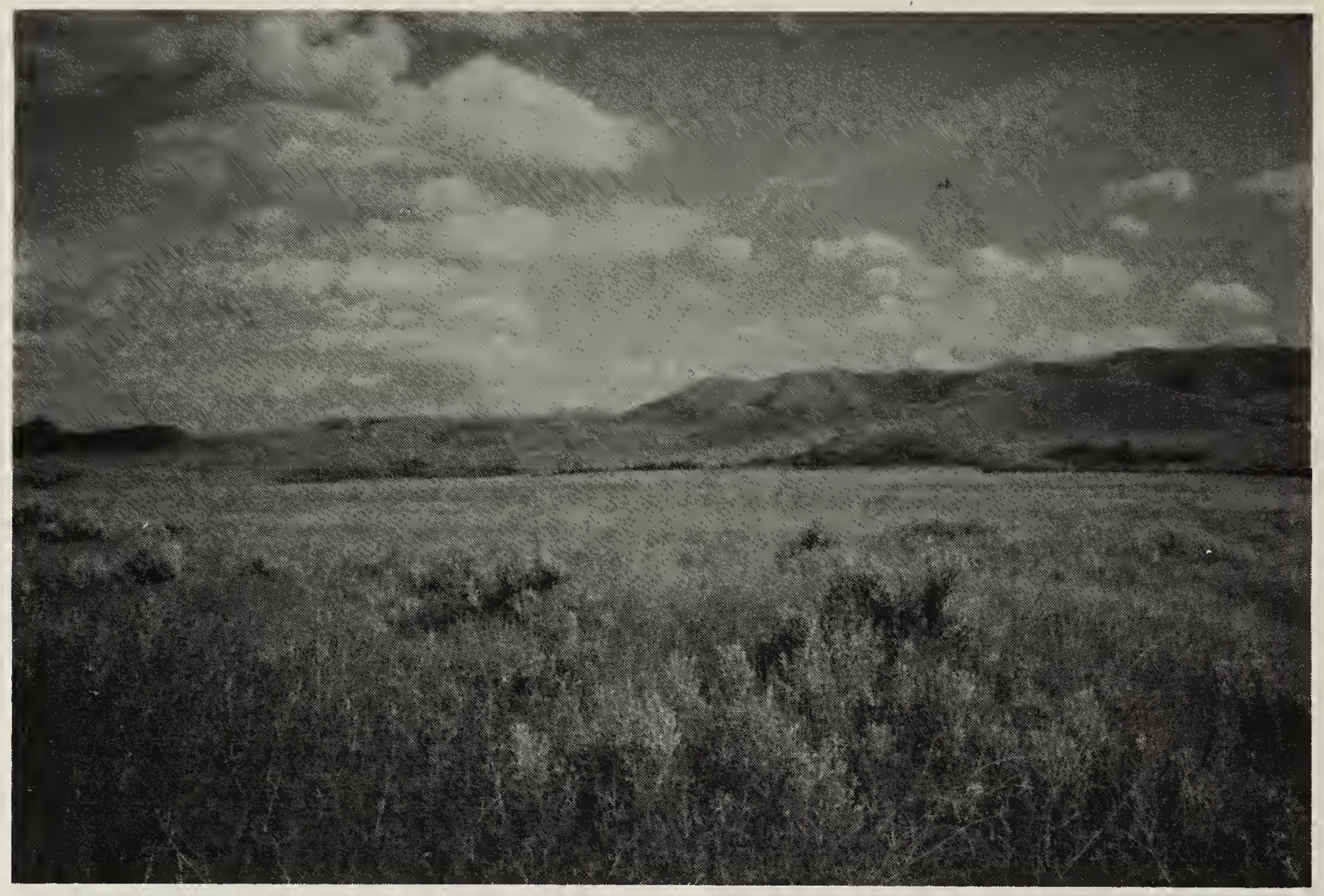

goes far beyond its capacity as an agricultural tract or even a wildlife preserve.

In the meantime, behind the scenes, the Nature Conservancy was hard at work approaching potential partners in ownership of what they hoped would be a new grasslands preserve. A professional assessor was employed, who spent a week driving and walking over the place, photographing and measuring, and then with his nose buried in government documents and land titles and who knows what all, before he came up with a price deemed by all involved to be fair market value. This was $\$ 600,000$ (which in fact, in view of the purchase price of over $\$ 300,000$ since then of a place something like a fifth of the new preserve's size, looks pretty puny). The Old Man On His Back Shortgrass Prairie and Heritage reserve was born. (The name has since been changed to The Old Man On His Back Prairie and Heritage Conservation Area.)
The new owners of the deeded land are the Nature Conservancy of Canada and Saskatchewan Environment and Resource Management, and Saskatchewan Agriculture and Food is the administrative authority of the leased land which is then leased by the Nature Conservancy, which, in turn, has leased it back to Peter Butala for a period of five years. (The Conservation Area is still a ranch and will be for up to the next five years.) The total project budget is $\$ 950,000$, which came from SaskPower $(\$ 350,000$ over two years), SERM's Fish and Wildlife Development Fund $(\$ 250,000)$, Environment Canada's Canadian Wildlife Service $(\$ 150,000)$, Saskatchewan Wildlife Federation $(\$ 40,000)$, the Butala's donation of $\$ 100,000$ in land, and the Eden Trust and private donors making up the balance.

On 18 July 1996 a ceremony was held on the land led by the Elders of the Nikaneet Reserve, (north of the Conservation Area in the Cypress Hills). This was followed by prayers 
led by elder Gordon Oakes, a feast, a few brief speeches, entertainment by young violinists Ben and Rebecca Beveridge of Saskatoon, and a Round Dance in which everyone (but two or three individuals) took part. The feeling in the hall at this point was so, for lack of a better word, warm, that in such a brief account words fail even a novelist. The Spirits of the Land, or of the Ancient People whose land it once was were felt by some to have been present.

The Farm Land Security Board has specified that there be no net loss in agricultural productivity which suits us, since it was Peter's abstemious ranching practices which kept the grass in good condition in the first place so that it could be turned into a conservation area. The challenge, as John Grant of The Nature Conservancy has said, is to do something innovative and at the same time of value to the local community. Peter would love to see bison running there again one day, and I am curious about a prairie restoration project, but such possibilities are still being discussed.

An advisory committee was established consisting of local people representing various interests tourism and the rural municipality, the Saskatchewan Stockgrowers, the oil company working in the area - plus representatives of the owners, (various branches of SERM and Sask. Agriculture and Food, and the Nature Conservancy) the leasees, and SaskPower representatives. Two meetings have so far been held, positions have been stated, subcommittees established, and the aims and possibilities of the Conservation Area are slowly being worked out. It is established that this is an opportunity to demonstrate the extent to which conservation and grazing interests can work together and benefit each other, and that the project is capable of being, and is intended to be, of great benefit to the local community. The first step will be a comprehensive survey and inventory of the flora and fauna to establish a base of information from which to determine policies, research directions, and community involvement. This will be begun as soon as possible.

There are bound to be tensions and sometimes conflicts when these various interest groups try to work together, but the effort to find common ground so as to serve each interest without destroying or damaging any other interest is one well worth making and in this regard, this project has the potential to break new ground, and to be an invaluable demonstration project for other endeavours of this kind.

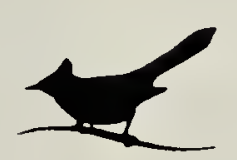

The Ruby-throated Hummingbird's wings beat 55 times per second when hovering, 61 times per second when backing up, and 75 times per second when flying forward.

In 1911, some ducks shot in Western Nebraska had small nuggets of gold in their gizzards, thus causing a gold rush. 